Review

\title{
Methods for Biomimetic Mineralisation of Human Enamel: A Systematic Review
}

\author{
Chris Ying Cao ${ }^{1}$, May Lei Mei ${ }^{1}$, Quan-li Li ${ }^{2}$, Edward Chin Man Lo ${ }^{1}$ and Chun Hung Chu ${ }^{1, *}$ \\ 1 Faculty of Dentistry, the University of Hong Kong, Hong Kong, China; \\ E-Mails: caoying0713@gmail.com (C.Y.C.); modelbaby1981@gmail.com (M.L.M.); \\ hrdplcm@hku.hk (E.C.M.L.) \\ 2 Stomatological Hospital and College, Anhui Medical University, \\ Key Lab. of Oral Diseases Research of Anhui Province, Hefei 230032, China; \\ E-Mail: u3001279@connect.hku.hk \\ * Author to whom correspondence should be addressed; E-Mail: chchu@hku.hk; \\ Tel.: +852-2859-0287; Fax: +852-2858-2532.
}

Academic Editor: Greta Patzke

Received: 23 April 2015 / Accepted: 18 May 2015 / Published: 26 May 2015

\begin{abstract}
Biomimetic mineralisation is an alternative restorative methodology that imitates the natural process of mineralisation. We aimed to systematically review the laboratory methods on the biomimetic mineralisation of demineralised enamel. A search in the PubMed, ScienceDirect, and ISI Web of Science databases was performed. Clinical trials, reviews, non-English articles, animal teeth, non-tooth substrates, and irrelevant studies were excluded. After screening the titles and abstracts of initially searched articles, 20 papers remained for full-text analysis. Eight articles were identified from the references of the remaining papers. A total of 28 studies were included in this systematic review. We found that protein or protein analogues were used to mimic the function of natural protein in 23 studies. Bioactive components inspired by mussel, an agarose hydrogel model, a glycerine-enriched gelatine technique, and ethylenediaminetetraacetic acid, were also used for biomimetic mineralisation of enamel. These laboratory studies reported success in the biomimetic mineralisation of enamel. Potential further research on the biomimetic mineralisation of enamel was discussed.
\end{abstract}

Keywords: biomimetic; mineralisation; enamel; proteins 


\section{Introduction}

Unlike the other mineralised tissues of the human body (i.e., bone, dentine, and cementum), mature enamel is acellular and has more than $95 \%$ mineral content and less than $1 \%$ organic material, thus, making it the hardest mineralised tissue in the human body [1]. The crystals found in enamel are nanorod-like hydroxyapatite (HAP) crystals with hierarchical levels of the enamel microstructure from the nanoscale to microscale [2]. The highly organised hierarchical microstructure (prism) provides dental enamel its unique strength and anti-abrasive properties [3]. During enamel biomineralisation, ameloblasts secrete proteins, such as amelogenin and ameloblastin, to mediate the crystallites to form the well-organised prism pattern [4]. Although the initial formation of enamel apatite occurs under a protein-rich gel-like matrix environment, the biological macromolecules are almost degraded or removed gradually. This makes mature enamel a non-living tissue. Damaged enamel is permanent and does not remodel. As the outermost layer covering the tooth, enamel is susceptible to dental caries and erosive wear. Traditional treatments replace the defective enamel with dental restorative materials, such as amalgam, composite resin, and ceramics, however, these restorative materials are very different from natural enamel in chemical components, crystal structures, and physicochemical properties. They cannot fit well with enamel at the interface of the enamel, and the restorative materials are at risk of marginal leakage, which leads to hypersensitivity and secondary caries. Therefore, it is of great interest for scientists in different fields to design an alternative strategy to repair defective enamel.

Enamel is relatively stable in a healthy oral environment with the presence of saliva. The demineralisation and remineralisation of enamel are continuously taking place at the tooth-pellicle-plaque-saliva interface [5]. It is well established that dental caries is a dynamic disease process caused by the imbalance between demineralisation and remineralisation [6]. This concept of dental caries provides the scope for remineralising early enamel carious lesions. Recently, various remineralising strategies have been developed to restore early enamel lesions and prevent enamel demineralisation, such as fluoride [7,8], surfactants [9], electrolytic deposition [10], hydrothermal methods [1,10], and hydrogen peroxide [11]. However, these methods are performed under stringent conditions, such as extremely low acidity or high electric field environments, which cannot be translated to clinical applications. Although surfactants, such as reverse micelles, mimic the natural biomineralisation process of enamel by modifying the HAP nanorods to self-assemble into an enamel-like structure, the biocompatibility limits their clinical application [12]. Dental enamel is produced by ameloblasts. Enamel formation is a protein-mediated biomineralisation process that takes place within an extracellular matrix $[4,13,14]$. Amelogenin is the major component of this matrix and it is essential for proper enamel biomineralisation [15]. Biomimetic mineralisation is a methodology that imitates the natural process of mineralisation [16]. It is generally accepted that the biomimetic synthesis of enamel-like apatite structures under a physiological condition is an alternative restorative pathway. This paper is a systematic review of the methods that successfully achieved the biomimetic mineralisation of demineralised human enamel. 


\section{Results}

The initial search from three electronic databases identified 2291 potential articles (294 in PubMed, 1567 in ScienceDirect, and 430 in ISI Web of Science), 2271 were excluded after the initial screening of titles and abstracts. After retrieving the full text of the remaining 20 articles, eight articles were found from the bibliographies of the included articles. Therefore, 28 articles were included in the systematic review (Figure 1). All 28 articles were in vitro studies published (including those Epub ahead of print) between 1997 and 2014.

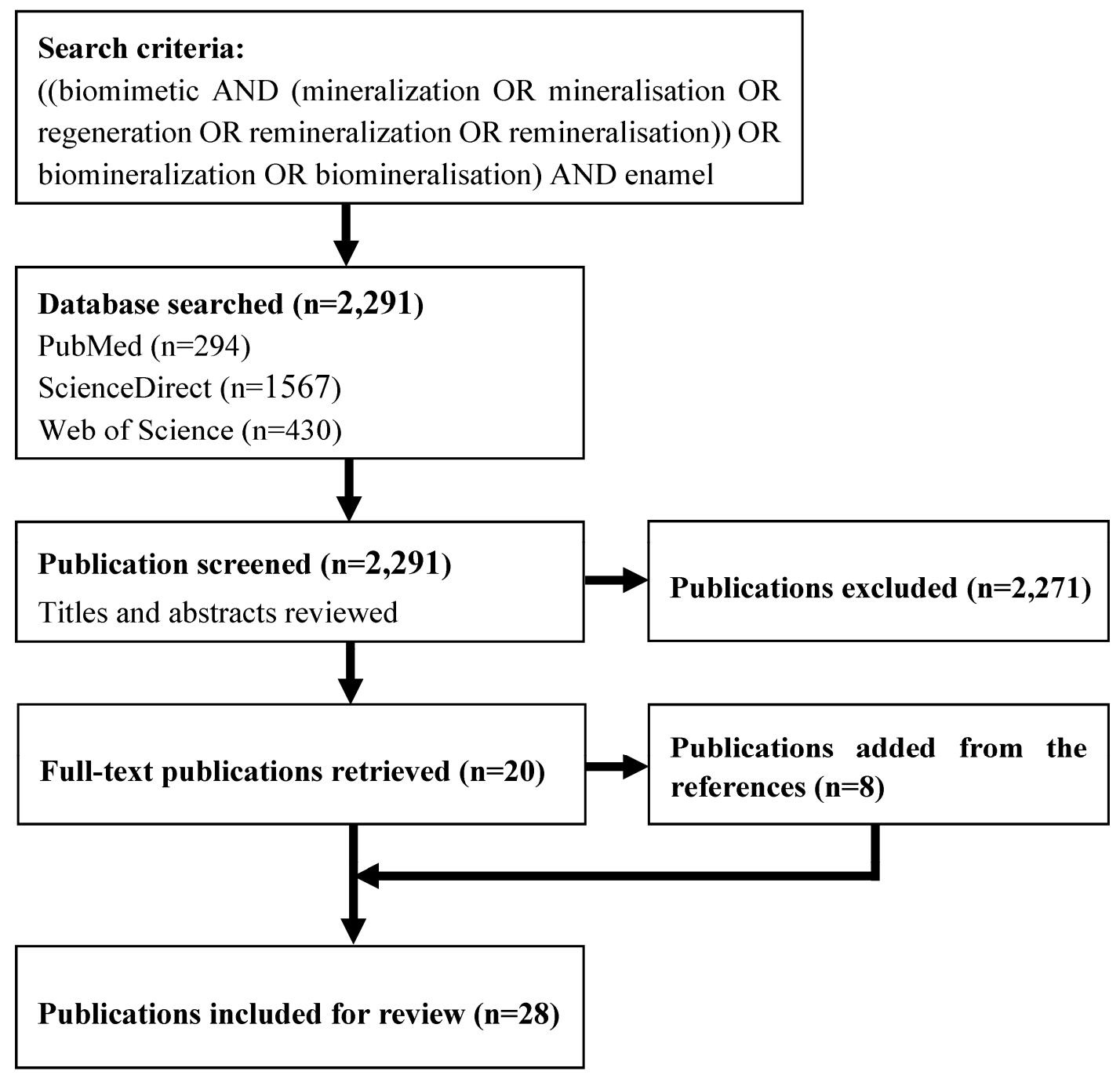

Figure 1. Flowchart of the search strategy.

Table 1 summarised the different methods of biomimetic mineralisation of enamel used in the included articles. Protein or protein analogues were used to mimic the function of natural proteins for the biomimetic mineralisation of enamel in 23 studies. Two studies used bioactive components inspired by mussel as a template to facilitate the hydroxyapatite nucleation on enamel $[17,18]$. A study constructed an agarose hydrogel model for the biomimetic mineralisation of enamel [19]. A study developed a glycerine-enriched gelatine technique to form fluorapatite layers on enamel [20]. A study used ethylenediaminetetraacetic acid (EDTA) as the mediating agent to reconstruct fluoride hydroxyapatite on enamel [21]. 
Mineral ions were provided by different remineralising mediums in the included articles. The most commonly used remineralising medium was artificial saliva. In addition, simulated body fluid (SBF), calcium phosphate remineralising solution/hydrogel, apatite nanocrystals slurry, bioactive glass slurry, and human saliva were also used. Fluoride at different concentrations was added in the remineralising mediums in 15 studies. The highest concentration of fluoride was $1100 \mathrm{ppm}$ and the lowest concentration was $0.45 \mathrm{ppm}$.

Different demineralising agents were used to treat enamel surface before biomimetic mineralisation. Phosphoric acid at concentration from $30 \%$ to $37 \%$ was used in 17 studies. In addition, a demineralising solution [22-26], citric acid [27], nitric acid [28-30], acidified gelatine gel [31], and a bi-layer demineralisation protocol of methylcellulose gel buffered with a lactic acid layer [32] were also used. In fact, the different demineralization agents are used to create two different models of enamel defects. The strong acid (phosphoric acid or nitric acid) is used to create an erosive lesion, while the demineralising solutions (or some gels) usually with $\mathrm{pH}$ of $\sim 4.6$ are used to generate artificial caries. These studies can regenerate enamel-like crystals on the enamel surface, and the main findings can be found in Table 1.

The functions of the proteins or protein analogues are summarised in Table 2. Amelogenin was added into a calcium phosphate solution containing fluoride $[28,29]$ or mixed with hydrogel containing calcium and phosphate $[26,33,34]$ to promote the orderly enamel-like structure formation. In one study, an enamel matrix derivative was mixed with calcium chloride agarose hydrogel to guide the continuous growth of crystals, prevent the crystal fusion of premature crystals, and control the nucleation and growth of the enamel prism-like crystals [35]. A polyamidoamine (PAMAM) dendrimer solution was applied to the etched enamel surface to provide nucleation sites and a mineralisation template for nanorod-like HAP formation with high uniformity [30,36,37]. Peptide was the most commonly used protein analogue. The sequence of the different peptides used in the included articles was summarised in Table 2. Only one study added peptide into a calcium phosphate solution containing fluoride to induce the formation of stable amorphous calcium phosphate (ACP) nano-precursors and prevent them from aggregation and precipitation [38]. In the other seven studies, a peptide solution was applied to the etched enamel surface to bind with the HAP surface, capture calcium and phosphate ions from artificial saliva, and promote HAP with a small average crystalline size [27,31,39-43]. Glutamic acid (Glu) was added into SBF to induce nano-apatite particle assembly and aggregation on the etched enamel surface, resulting in the regeneration of the enamel-like structure [44]. Polyacrylic acid (PAA) was added to bioactive glass and applied to the etched enamel surface to promote the oriented bundle formation, release $\mathrm{Ca}$ and $\mathrm{P}$ ions to form an $\mathrm{ACP}$ layer, and act as a reservoir of ions available for remineralisation [32]. The nano-complexes of the phosphorylated chitosan-ACP solution were applied to the etched enamel surface to act as the aggregates of prenucleation clusters, to provide stable ACP, and to adsorb on the enamel surface [25]. Etched enamel was incubated with a casein phosphopeptide-amorphous calcium phosphate (CPP-ACP) solution [22], coated with CPP-ACP paste [23], or brushed with CPP-ACP paste [24] to act as a calcium and phosphate reservoir and promote enamel subsurface lesion remineralisation. 
Table 1. Summary of the in vitro studies on biomimetic mineralisation on human enamel.

\begin{tabular}{|c|c|c|c|c|}
\hline Authors, Year [Ref.] & Surface Treatment & Biomineralisation Method & Sources of $\mathrm{Ca}$ and $\mathrm{P}$ & Main Finding \\
\hline Reynolds, 1997 [22] & Demineralising solution (4d) & СРP-АCP & $\mathrm{CaCl}_{2}$ solution, $\mathrm{K}_{3} \mathrm{PO}_{4}$ buffer & $\begin{array}{l}\text { The CPP-stabilised CaP solution can remineralise subsurface } \\
\text { enamel lesions. }\end{array}$ \\
\hline Busch, $2004[20]$ & $30 \%$ PA $(30 \mathrm{~s})$ & Glycerin-enriched gelatin $620 \mathrm{ppm} \mathrm{F}$ & $\mathrm{CaCl}_{2}$ solution, $\mathrm{PO}_{4}$ gelatin & Ordered enamel-like mineral was induced on human teeth. \\
\hline Kirkham et al., 2007 [31] & Acidified gelatine gel (6w) & Peptide & pH cycling & $\begin{array}{l}\text { Peptide treatment increased remineralisation } \\
\text { and inhibited demineralisation. }\end{array}$ \\
\hline Kumar et al., 2008 [23] & Demineralising solution $(4 \mathrm{~d})$ & CPP-ACP 1100 ppm F & $\mathrm{pH}$ cycling & CPP-ACP remineralised initial enamel lesions. \\
\hline Fan et al., 2009 [28] & $3 \% \mathrm{HNO}_{3}$ solution $(50 \mathrm{~s})$ & Amelogenin 0.45 ppm F & Calcification solution & $\begin{array}{l}\text { The synthetic nanorod crystals formed on etched enamel in } \\
\text { the presence of amelogenin. }\end{array}$ \\
\hline Xie et al., 2011 [21] & $37 \% \mathrm{PA}(30 \mathrm{~s})$ & EDTA 950 ppm F & $\begin{array}{l}\text { Ca-EDTA complex-phosphate } \\
\text { solution } \\
\end{array}$ & $\begin{array}{l}\text { EDTA induced the assembly of hexagonal } \\
\text { prism-like FHAP microcrystals. }\end{array}$ \\
\hline Jayarajan et al., 2011 [24] & Demineralising solution $(5 \mathrm{~h})$ & СРP-АCР, СРP-АCРF 900 ppm & Artificial saliva & $\begin{array}{l}\text { CPP-ACPF showed more amount of } \\
\text { remineralisation than CPP-ACP. }\end{array}$ \\
\hline Fan et al., 2011 [29] & $5 \% \mathrm{HNO}_{3}$ solution $(30 \mathrm{~s})$ & Amelogenin 1-10 ppm F & Remineralisation solution & Densely packed arrays of FHAP nanorods were observed. \\
\hline Hsu et al., 2011 [39] & $35 \%$ PA (30s) & Peptide & SBF & $\begin{array}{l}\text { The nanomechanical properties of the acid-demineralised } \\
\text { enamel were greatly improved. }\end{array}$ \\
\hline Hsu et al., 2011 [42] & $35 \%$ PA $(30 \mathrm{~s})$ & Peptide & SBF & $\begin{array}{l}\text { Peptide promoted the uniform deposition of nano-crystalline } \\
\qquad \mathrm{CaP} \text { over enamel surfaces. }\end{array}$ \\
\hline Li et al., 2011 [44] & $37 \%$ PA $(10 \mathrm{~s})$ & Glu-apatite nanoparticles & SBF & Nanoparticles turned into rod-like crystals on enamel surface. \\
\hline Zhou et al., 2012 [17] & $37 \%$ PA $(2 \mathrm{~m})$ & Polydopamine $1 \mathrm{ppm} \mathrm{F}$ & Calcification solution & $\begin{array}{l}\text { No significant difference was observed in the remineralisation } \\
\text { of enamel, except in dentine. }\end{array}$ \\
\hline Fan et al., 2012 [26] & Demineralising solution ( $3 \mathrm{~d})$ & Amelogenin 5 ppm F & Artificial saliva & $\begin{array}{l}\text { Application of the amelogenin-hydrogel significantly } \\
\text { improved enamel hardness. }\end{array}$ \\
\hline Chung et al., 2012 [40] & $34 \%$ PA $(15 s)$ & Peptide & Artificial saliva & $\begin{array}{l}\text { Peptide promoted the uniform deposition of apatites with } \\
\text { small crystalline size. }\end{array}$ \\
\hline Li et al., 2013 [18] & $37 \%$ PA $(15 \mathrm{~s})$ & Nacre water-soluble matrix & SBF & $\begin{array}{l}\text { Water-soluble matrix facilitated the } \\
\text { formation of HAP nanorods. }\end{array}$ \\
\hline Chung et al., 2013 [27] & $1 \mathrm{M}$ citric acid $(2 \mathrm{~m})$ & Peptide & Artificial saliva & Peptide promoted the formation of nano-HAP crystals. \\
\hline
\end{tabular}


Table 1. Cont.

\begin{tabular}{|c|c|c|c|c|}
\hline Authors, Year [Ref.] & Surface Treatment & Biomineralisation Method & Sources of $\mathrm{Ca}$ and $\mathrm{P}$ & Main Finding \\
\hline Chen et al., 2013 [30] & $3 \% \mathrm{HNO}_{3}$ solution $(50 \mathrm{~s})$ & PAMAM 1 ppm F & Calcification solution & $\begin{array}{l}\text { PAMAM could induce the formation of HAP crystals on } \\
\text { demineralised enamel. }\end{array}$ \\
\hline Ruan et al., 2013 [33] & $30 \% \mathrm{PA}(30 \mathrm{~s})$ & Amelogenin $136 \mathrm{ppm} \mathrm{F}$ & $\begin{array}{l}\text { Amelogenin-CaP hydrogel, } \\
\text { artificial saliva }\end{array}$ & The enamel-like layer was formed on natural enamel. \\
\hline Wu et al., 2013 [36] & $37 \%$ PA $(45 s)$ & PAMAM & Artificial saliva & $\begin{array}{l}\text { PAMAM could induce nanorod-like HAP remineralisation on } \\
\text { acid-etched enamel. }\end{array}$ \\
\hline Chung et al., 2013 [41] & $34 \%$ PA (30s) & Peptide & Artificial saliva & $\begin{array}{l}\text { Peptide attracted ions from artificial saliva to form HAP } \\
\text { crystals and fill enamel caries. }\end{array}$ \\
\hline Chung et al., 2013 [43] & $34 \%$ PA (30s) & Peptide & Artificial saliva & Peptide promoted the deposition of small-grain HAP crystals. \\
\hline Cao et al., 2014 [19] & $37 \%$ PA (60s) & Agarose hydrogel 500 ppm F & $\begin{array}{c}\mathrm{CaCl}_{2} \text { hydrogel, } \\
\text { Phosphate solution }\end{array}$ & $\begin{array}{c}\text { Enamel prism-like tissue was generated } \\
\text { on etched enamel surface. }\end{array}$ \\
\hline Zhang et al., 2014 [25] & Demineralising solution $(7 \mathrm{~d})$ & Phosphorylated chitosan-ACP & Pchi-ACP solution & $\begin{array}{l}\text { Remineralising rate of Pchi-ACP treatment was higher than } \\
\text { that of fluoride treatment. }\end{array}$ \\
\hline Ruan et al., 2014 [34] & $30 \% \mathrm{PA}(30 \mathrm{~s})$ & Amelogenin 0.45 ppm F & $\begin{array}{l}\text { Amelogenin-CaP hydrogel, } \\
\text { artificial saliva }\end{array}$ & $\begin{array}{l}\text { Enamel-like organized apatite crystals can be formed in } \\
\text { amelogenin-chitosan system. }\end{array}$ \\
\hline Milly et al., 2014 [32] & $\begin{array}{l}8 \% \text { methylcellulose gel, } \\
\text { lactic acid }(14 \mathrm{~d})\end{array}$ & Polyacrylic acid, Bioactive glass & Bioactive glass slurry & $\begin{array}{c}\text { BAG and PAA-BAG treatments enhanced remineralisation of } \\
\text { enamel white spot lesions. }\end{array}$ \\
\hline Cao et al., 2014 [35] & $37 \%$ PA $(60 s)$ & Enamel matrix derivative $500 \mathrm{ppm} \mathrm{F}$ & $\begin{array}{c}\text { EMD- } \mathrm{CaCl}_{2} \text { hydrogel, } \\
\text { Phosphate solution }\end{array}$ & $\begin{array}{l}\text { EMD facilitated enamel prism-like tissue formation on } \\
\text { demineralised human enamel. }\end{array}$ \\
\hline Chen et al., 2014 [37] & $37 \%$ PA $(45 \mathrm{~s})$ & PAMAM & Artificial saliva & $\begin{array}{l}\text { PAMAM could produce an enamel prism-like } \\
\text { structure on acid-etched enamel. }\end{array}$ \\
\hline Li et al., 2014 [38] & $37 \%$ PA (60s) & Oligopeptide 1 ppm F & $\begin{array}{l}\text { Metastable calcium phosphate } \\
\text { solution }\end{array}$ & $\begin{array}{l}\text { Oligopeptide induced the formation of HAP } \\
\text { crystals on etched enamel. }\end{array}$ \\
\hline
\end{tabular}

BAG—Bioactive glass; CPP—Casein phosphopeptide; CPP-ACP—Casein phosphopeptide-amorphous calcium phosphate; CPP-ACPF—Casein phosphopeptide-amorphous calcium phosphate fluoride; EDTA—Ethylenediamine tetraacetic acid; EMD—Enamel matrix derivative; F—fluoride; FHAP—Fluoridated hydroxyapatite; Glu—glutamic acid; HAP—Hydroxyapatite; PA—Phosphoric acid; Pchi—Phosphorylated chitosan; PAA—Polyacrylic acid; PAMAM—Poly (amido amine) dendrimer; PVP—poly(vinylpyrrolidone); SBF—Simulated body fluid. 
Table 2. Protein or its analogues and their functions in biomimetic mineralisation of human enamel.

\begin{tabular}{|c|c|c|}
\hline Protein or Its Analogues & Function of Protein or Protein Analogues & Approach [Ref.] \\
\hline Amelogenin & $\begin{array}{l}\text { - } \text { Promote the oriented bundle formation } \\
\text { - Mediate the orderly enamel-like structure formation } \\
\text { - Control the organised growth of apatite crystals } \\
\text { - Form transitional complexes with ACP } \\
\text { - Promote the hydrolysis of ACP to stable HAP } \\
\text { - Stabilise the Ca-P clusters and guide their arrangement into } \\
\text { linear chains }\end{array}$ & $\begin{array}{c}\text { Amel } \_\mathrm{Ca} / \mathrm{P} / \mathrm{F} \text { solution: }[28,29] \\
\text { Amel— } \mathrm{Ca} / \mathrm{P} \text { hydrogel: } \\
{[26,33,34]}\end{array}$ \\
\hline EMD & $\begin{array}{l}\text { - Affect the formation of enamel prism-like tissue } \\
\text { - Guide the continuous growth of crystals } \\
\text { - Prevent the crystal fusion of premature crystals } \\
\text { - Control crystal morphology and subsequent elongation } \\
\text { - Control the nucleation and growth of the crystals }\end{array}$ & $\begin{array}{c}\text { EMD — Ca agarose hydrogel: } \\
{[35]}\end{array}$ \\
\hline $\begin{array}{l}\text { PAMAM dendrimers: } \\
\text { PAMAM-COOH [30] } \\
\text { ALN-PAMAM-COOH [36] } \\
\text { PAMAM-PO }{ }_{3} \mathrm{H}_{2}[37]\end{array}$ & $\begin{array}{l}\text { - Absorb onto the etched enamel surface } \\
\text { - } \quad \text { Provide nucleation sites and mineralisation template for HAP } \\
\text { - } \quad \text { Regulate the growth of crystals } \\
\text { - Induce nanorod-like HAP with high uniformity } \\
\text { - Induce in situ remineralisation of HAP on etched enamel }\end{array}$ & $\begin{array}{c}\text { PAMAM — etched enamel: } \\
{[30,36,37]}\end{array}$ \\
\hline $\begin{array}{c}\text { Peptide: } \\
\text { 3NSS [27,41,43] } \\
\text { QQRFEWEFEQQ [31] } \\
\mathrm{C}_{18 \mathrm{H}{ }_{35} \mathrm{O}-\mathrm{TKREEVD} \mathrm{[38]}} \\
\text { 8DSS }[39,42] \\
\text { 3DSS [40] }\end{array}$ & $\begin{array}{l}\text { - } \text { Form 3D biomimetic scaffolds capable of nucleating HAP } \\
\text { - } \text { Capture } \mathrm{Ca} \text { and } \mathrm{P} \text { ions from artificial saliva } \\
\text { - } \quad \text { Limit } \mathrm{Ca} \text { and } \mathrm{P} \text { ions to depart from the demineralised enamel } \\
\text { - } \text { Possess a high affinity to bind with the HAP surface } \\
\text { - } \quad \text { Promote HAP with a small average crystalline size } \\
\text { - Induce formation of stable ACP nano-precursors and prevent } \\
\text { them from aggregation and precipitation }\end{array}$ & $\begin{array}{l}\text { Peptide—etched enamel: } \\
\qquad[27,31,39-43] \\
\text { Peptide—Ca/P/F solution: [38] }\end{array}$ \\
\hline Glutamic acid & $\begin{array}{l}\text { - Induce the nano apatite assembly on enamel } \\
\text { - Provide the active sites to control enamel formation } \\
\text { - Interact with a (001) surface of the nano apatite } \\
\text { - Induce the oriented aggregation of nano apatite }\end{array}$ & Glutamic acid—SBF: [44] \\
\hline Polyacrylic acid & $\begin{array}{l}\text { - Sequester calcium and phosphate ions } \\
\text { - Form amorphous calcium phosphate nano-precursors } \\
\text { - Reduce the abrasiveness of bioactive glass particles }\end{array}$ & $\begin{array}{l}\text { Polyacrylic acid — bioactive } \\
\text { glass: [32] }\end{array}$ \\
\hline Phosphorylated chitosan & $\begin{array}{l}\text { - Bind calcium ions to form nucleating sites } \\
\text { - Stabilise ACP to form the nano-complexes of Pchi-ACP } \\
\text { - Adsorb onto the surfaces of HAP crystals } \\
\text { - Inhibit spontaneous precipitation of calcium phosphate }\end{array}$ & Pchi- $\mathrm{CaPO}_{4}$ solution: [25] \\
\hline Casein phosphopeptide & $\begin{array}{l}\text { - Stabilise calcium, phosphate, and hydroxide ions } \\
\text { - Prevent spontaneous precipitation of calcium phosphate } \\
\text { - Promote enamel subsurface lesion remineralisation }\end{array}$ & $\begin{array}{c}\mathrm{CPP}-\mathrm{CaPO}_{4} \text { solution: }[22] \\
\text { CPP_ACP Paste: }[23,24]\end{array}$ \\
\hline
\end{tabular}

QQRFEWEFEQQ_-Glutamine-Glutamine-Arginine-Phenylalanine-Glutamic acid-Tryptophan-Glutamic acid-Phenylalanine-Glutamic acid-Glutamine-Glutamine; SBF-Simulated Body Fluid; TKREEVD—Threonine-Lysine-Arginine-Glutamic acid-Glutamic acid-Valine-Aspartic acid. 


\section{Discussion}

Enamel biomineralisation is a highly regulated process involving precise genetic control, as well as protein-protein interactions, protein-mineral interactions, and interactions involving the cell membrane. Ameloblast secretes enamel matrix proteins in the extracellular space between ameloblasts and dentine to control the initiation, orientation, nucleation, and growth of HAP crystals [4]. Amelogenin is the main secretory product of ameloblasts, making up more than $90 \%$ of the organic component in enamel [45]. The assembly of amelogenin has been shown to be crucial for the proper development of enamel crystallites. However, mature enamel is unable to heal and repair itself after demineralisation of the surface and subsequent cavitation. Biomimetic strategies for enamel regeneration may have the potential to repair enamel surface lesions. It is, therefore, important to study the structures and functions of amelogenin for the biomimetic mineralisation of enamel.

Iijima and Moradian-Oldak used the natural amelogenin in vitro to control calcium and phosphate crystallisation, and they found the growth of nanorod-like apatite crystals with a similar habit, size, and orientation to natural enamel [46]. Although this study was carried out through a cation selective membrane system as a model of tooth enamel formation, it highlighted the potential of amelogenin in the design and development of enamel-like biomaterials. Fan et al. used amelogenin with a modified biomimetic deposition method to remineralise the surface of etched enamel, and they were able to form mineral layers containing organised needle-like fluoridated hydroxyapatite crystals [28]. A follow-up study by Fan et al. reported the conditions of supersaturation degree, fluoride, and amelogenin concentration on the formation of densely packed fluoridated HAP on etched enamel in vitro [29]. An amelogenin-containing chitosan hydrogel was developed for superficial enamel reconstruction. The mechanism of the enamel reconstruction is through amelogenin supramolecular assembly, stabilising Ca-P clusters, and guiding their arrangement into linear chains [33,34]. However, it was difficult to extract and purify natural proteins. Thus, researchers fabricated protein analogues that could play the roles of the proteins in the biomineralisation process. Peptide/oligopeptide was fabricated to promote the formation of HAP crystals. A peptide with numerous repetitive nucleotide sequences of Aspartic-Serine-Serine (DSS), based on the sequence of dentin phosphoprotein had a high affinity to calcium phosphate compounds and promoted the formation of HAP crystals [39,40,42]. Triplet-repeating Asparagine-serine-serine (3NSS) peptide, a derivative of the DSS peptide, was designed by replacing the $\mathrm{COOH}$ group in Aspartic with the $\mathrm{CONH}_{2}$ group. The authors declared that enamel remineralisation with this 3 NSS peptide showed a higher degree of recovery compared to DSS peptide. This might due to the difference between the ionic-attraction ability of a $\mathrm{COOH}$ group and $\mathrm{CONH}_{2}$ group $[27,41,43]$. Kirkham et al. designed a self-assembling peptide $\left(\mathrm{P}_{11}-4\right.$, Ace-Gln-Gln-Arg-Phe-Glu-Trp-Glu-Phe-Glu-Gln-Gln-NH 2 , which could provide a biomimetic scaffold for HAP nucleation [31]. Recently, Li et al. fabricated an oligopeptide amphiphile $\left(\mathrm{C}_{18} \mathrm{H}_{35} \mathrm{O}\right.$-Thr-Lys-Arg-Glu-Glu-Val-Asp), which consisted of a derivative of stearic acid and a hydrophilic C-terminal amino residue of amelogenin [38]. In general, the peptides were shown to increase the remineralisation of enamel. PAMAM dendrimers have also been used as "artificial proteins" to evaluate their binding capacity and the surface charge with enamel crystals $[12,47]$. PAMAM-COOH acted as the organic template on the demineralized enamel surface to induce the formation of HAP crystals with the same structure, orientation and mineral phase of the natural 
enamel [30]. Due to the specific adsorption on HAP, alendronate was conjugated to PAMAM-COOH and induced in situ remineralisation of HAP on acid-etched enamel [36]. PAMAM- $\mathrm{PO}_{3} \mathrm{H}_{2}$ was designed with a similar dimensional scale and peripheral functions to that of amelogenin in enamel [37]. These dendrimers formed nanospheres and had a possible role in guiding crystal growth. In addition to the proteins and protein analogues, there are a number of other available biopolymers that were used in the biomimetic formation of HAP. These were predominantly polysaccharides such as agarose [19] and gelatine [20].

The synthesis of enamel-like structures based on the aforementioned approaches requires several days. In recent years, the biomimetic treatment of early caries lesions through the application of various types of bioactive materials with protein analogues has received considerable attention such as PAA-bioactive glass [32] and Glu-apatite nanoparticles [44]. PAA-bioactive glass was applied as slurry to avoid any damage to the enamel lesion structure. Bioactive glass is a ceramic material consisting of a similar amount of sodium, calcium, phosphate, and silicate ions, which are elements naturally found in the human body. The release of ions requires contact with artificial saliva. These bioactive materials dissolve in saliva to liberate ions that diffuse into the enamel subsurface lesion. PAA was used as an analogue to sequester calcium and phosphate ions released from bioactive glass to form amorphous calcium phosphate nano-precursors. The PAA-bioactive glass had the potential to deliver calcium and phosphate ions to subsurface enamel lesions. In an aqueous environment, the protonation of the $\mathrm{Si}-\mathrm{O}$ groups formed rich silanols on the etched enamel surface. It generated an electronegative surface that provided heterogeneous nucleation sites for the formation of HAP crystals [48]. Amino acids are the basic building blocks of proteins. There is $15-20 \%$ Glu in the amino acid composition of amelogenin, and the roles of Glu in the biomimetic mineralisation of enamel have been investigated. Glu has two carboxylate groups that could be preferentially adsorbed onto the (001) face of apatite to induce the oriented crystallisation along the $c$-axis. Several studies demonstrated that apatite nano-particles have the potential to remineralise the initial enamel caries lesions in vitro. Nanostructured apatite crystals exhibit high levels of biomimetic properties and surface activity. Apatite nano-particles can act as a calcium and phosphate reservoir that helps to maintain a topical state of super-saturation of these ions on an enamel surface. As a building block, apatite nano-particles could adsorb onto the enamel surface and assemble into oriented HAP crystals under the control of Glu. This resulted in the regeneration of the enamel-like structure under physiological conditions [44].

In biology, the biomineralisation process is an organic matrix particle-mediated non-classical crystallisation pathway involving a mesoscopic transformation process. The presence of transient ACP nanoprecursors has been found during enamel biomineralisation [49]. The formation and stabilisation of amorphous nanoprecursors is an important step in the biomimetic mineralisation of enamel. CPP obtained from milk is an analogue of the proteins involved in the biomineralisation of teeth. CPP contains clusters of phosphorylated serine residues and can, thus, stabilise calcium and phosphate ions through the formation of amorphous nano-complexes [22-24]. CPP-ACP provided a reservoir of calcium and phosphate ions to maintain a state of super-saturation on the enamel surface, resulting in a significant remineralising effect on enamel subsurface lesions [50]. Based on the influence of phosphorylated proteins in enamel biomineralisation, nano-complexes of phosphorylated chitosan and ACP were synthesised to remineralise early enamel caries [25]. These results indicated that the application of natural protein analogues might be an effective strategy to stabilise the amorphous nanoprecursors. 
Fluoride was used to prevent and arrest caries by inhibiting bacterial metabolism, inhibiting demineralisation, and enhancing remineralisation. Fluoride ions entered into the directive lattice of HAP crystals and replaced hydroxide ions or adsorbed onto the crystal surface to attract calcium and phosphate ions, resulting in the formation of fluoridated HAP [51]. Fluoridated HAP contains approximately 30,000 ppm fluoride and has a very low solubility in acid. In this review, fluoride was added in different remineralising mediums in 15 studies. The concentration of the fluoride used varied greatly between the studies. Fluoride had a significant effect on the morphology of calcium phosphate crystals. The morphology and orientation of the formed crystals were tuneable by the fluoride concentration. Iijima et al. discovered the conversion of ribbon-like octacalcium phosphate into needle-like HAP in a membrane system in the presence of $2 \mathrm{ppm}$ fluoride [52]. Fan et al. reported that a critical fluoride at $5 \mathrm{ppm}$ in remineralisation solutions with a $\mathrm{pH}$ of 6.74 and $5 \mathrm{mM} \mathrm{Ca}^{2+}$ was required to induce the transition from plate-like octacalcium phosphate to octacalcium phosphate rod-like HAP that regenerated on etched enamel surface [29]. The critical concentration of fluoride changed when the $\mathrm{pH}$ and the concentrations of Calcium and amelogenin were changed. Rod-like fluoridated HAP was reported in a hydrogel model with a high concentration of fluoride [19]. However, despite the predominant beneficial effect of fluoride on enamel remineralisation, the dental fluorosis induced by excessive intake of fluoride could not be ignored, especially with the application of these products to children.

Apparent progress has been made to understand the process of HAP biomineralisation of enamel, which has the potential to remineralise defective enamel lesions. A number of biomimetic mineralisation methods were reported and published in the literature. However, the overall mechanism of remineralisation in vivo has not yet been clarified. Further research is necessary to assess in detail whether the biomimetic mineralisation approaches for enamel caries therapy will be suitable and applicable in daily dental practice. Furthermore, an easy-to-apply, fast-growing system for enamel-like structure regeneration is necessary for clinical use.

\section{Methods}

Three electronic databases (PubMed, ScienceDirect, and ISI Web of Science) were systematically searched to identify publications before 1 January 2015. The keywords used were: ((biomimetic AND (mineralization OR mineralisation OR regeneration OR remineralization OR remineralisation)) OR biomineralization OR biomineralisation) AND enamel. No publication year or language limit was used. The titles and abstracts of identified articles were independently reviewed by two authors. Duplicated articles were removed. Clinical trials, reviews, non-English articles, animal teeth, non-tooth substrates, and irrelevant studies were excluded. The articles were further reviewed with full-texts if the articles met the inclusion criteria (biomimetic mineralisation methods for demineralised human enamel in vitro). Manual screening was conducted on the reference lists of all included articles to identify relevant articles. Disagreements about the inclusion or exclusion of a study were discussed with a third author for a final decision. Data extraction was conducted by one author from full-texts and evaluated by another one. Similar information mentioned in the included articles was summarised (such as protein and protein analogues). 


\section{Conclusions}

Many studies with different methods reported success in the biomimetic mineralisation of enamel, including the use of protein and protein analogues, bioactive materials or components, an agarose hydrogel model, a glycerine-enriched gelatine technique, and ethylenediaminetetraacetic acid.

\section{Acknowledgments}

This work was supported by the General Research Fund (HKU 760413M).

\section{Author Contributions}

Chris Ying Cao and May Lei Mei searched the databases and prepared the manuscript. Quan-li Li regulated the data extraction. Edward Chin Man Lo and Chun Hung Chu revised the manuscript. All authors read and approved the final manuscript.

\section{Conflicts of Interest}

The authors declare no conflict of interest.

\section{References}

1. Chen, H.F.; Tang, Z.Y.; Liu, J.; Sun, K.; Chang, S.R.; Peters, M.C.; Mansfield, J.F.; Czajka-Jakubowska, A.; Clarkson, B.H. Acellular synthesis of a human enamel-like microstructure. Adv. Mater. 2006, 18, 1846-1851.

2. Veis, A. Materials science. A window on biomineralization. Science 2005, 307, 1419-1420.

3. Cui, F.Z.; Ge, J. New observations of the hierarchical structure of human enamel, from nanoscale to microscale. J. Tissue Eng. Regen. Med. 2007, 1, 185-191.

4. Fincham, A.G.; Moradian-Oldak, J.; Simmer, J.P. The structural biology of the developing dental enamel matrix. J. Struct. Biol. 1999, 126, 270-299.

5. Aoba, T. Solubility properties of human tooth mineral and pathogenesis of dental caries. Oral Dis. 2004, 10, 249-257.

6. Featherstone, J.D. Dental caries: A dynamic disease process. Aust. Dent. J. 2008, 53, 286-291.

7. Yin, Y.J.; Yun, S.; Fang, J.S.; Chen, H.F. Chemical regeneration of human tooth enamel under near-physiological conditions. Chem. Commun. 2009, 5892-5894.

8. Fan, Y.; Sun, Z.; Moradian-Oldak, J. Effect of fluoride on the morphology of calcium phosphate crystals grown on acid-etched human enamel. Caries Res. 2009, 43, 132-136.

9. Fowler, C.E.; Li, M.; Mann, S.; Margolis, H.C. Influence of surfactant assembly on the formation of calcium phosphate materials-A model for dental enamel formation. J. Mater. Chem. 2005, 15, 3317-3325.

10. Ye, W.; Wang, X.X. Ribbon-like and rod-like hydroxyapatite crystals deposited on titanium surface with electrochemical method. Mater. Lett. 2007, 61, 4062-4065.

11. Yamagishi, K.; Onuma, K.; Suzuki, T.; Okada, F.; Tagami, J.; Otsuki, M.; Senawangse, P. Materials chemistry: A synthetic enamel for rapid tooth repair. Nature 2005, 433, 819. 
12. Chen, H.F.; Clarkson, B.H.; Sun, K.; Mansfield, J.F. Self-assembly of synthetic hydroxyapatite nanorods into an enamel prism-like structure. J. Colloid. Interface Sci. 2005, 288, 97-103.

13. Moradian-Oldak, J. Protein-mediated enamel mineralization. Front. Biosci. 2012, 17, 1996-2023.

14. Ruan, Q.; Moradian-Oldak, J. Amelogenin and enamel biomimetics. J. Mater. Chem. B 2015, 3, 3112-3129.

15. Margolis, H.C.; Beniash, E.; Fowler, C.E. Role of macromolecular assembly of enamel matrix proteins in enamel formation. J. Dent. Res. 2006, 85, 775-793.

16. Cao, Y.; Liu, W.; Ning, T.; Mei, M.L.; Li, Q.L.; Lo, E.C.; Chu, C.H. A novel oligopeptide simulating dentine matrix protein 1 for biomimetic mineralization of dentine. Clin. Oral Investig. 2014, 18, 873-881.

17. Zhou, Y.Z.; Cao, Y.; Liu, W.; Chu, C.H.; Li, Q.L. Polydopamine-induced tooth remineralization. ACS Appl. Mater. Interfaces 2012, 4, 6901-6910.

18. Li, X.; Pan, D.M.; Lin, S.; Zhuang, Z.Y.; Lin, Z. Facile in vitro hydroxyapatite remineralization of human enamel with remarkable hardness. CrystEngComm. 2013, 15, 4351-4356.

19. Cao, Y.; Mei, M.L.; Li, Q.L.; Lo, E.C.; Chu, C.H. Agarose hydrogel biomimetic mineralization model for the regeneration of enamel prismlike tissue. ACS Appl. Mater. Interfaces 2014, 6, 410-420.

20. Busch, S. Regeneration of human tooth enamel. Angew. Chem. Int. Edit. 2004, 43, 1428-1431.

21. Xie, R.Q.; Feng, Z.D.; Li, S.W.; Xu, B.B. EDTA-assisted self-assembly of fluoride-substituted hydroxyapatite coating on enamel substrate. Cryst. Growth. Des. 2011, 11, 5206-5214.

22. Reynolds, E.C. Remineralization of enamel subsurface lesions by casein phosphopeptide-stabilized calcium phosphate solutions. J. Dent. Res. 1997, 76, 1587-1595.

23. Kumar, V.L.N.; Itthagarun, A.; King, N.M. The effect of casein phosphopeptide-amorphous calcium phosphate on remineralization of artificial caries-like lesions: An in vitro study. Aust. Dent. J. 2008, 53, 34-40.

24. Jayarajan, J.; Janardhanam, P.; Jayakumar, P.; Deepika. Efficacy of CPP-ACP and CPP-ACPF on enamel remineralization-An in vitro study using scanning electron microscope and diagnodent. Indian J. Dent. Res. 2011, 22, 77-82.

25. Zhang, X.; Li, Y.; Sun, X.; Kishen, A.; Deng, X.; Yang, X.; Wang, H.; Cong, C.; Wang, Y.; Wu, M. Biomimetic remineralization of demineralized enamel with nano-complexes of phosphorylated chitosan and amorphous calcium phosphate. J. Mater. Sci. Mater. Med. 2014, 25, 2619-2628.

26. Fan, Y.; Wen, Z.T.; Liao, S.; Lallier, T.; Hagan, J.L.; Twomley, J.T.; Zhang, J.F.; Sun, Z.; Xu, X. Novel amelogenin-releasing hydrogel for remineralization of enamel artificial caries. J. Bioact. Compat. Polym. 2012, 27, 585-603.

27. Chung, H.Y.; Huang, K.C. Effects of peptide concentration on remineralization of eroded enamel. J. Mech. Behav. Biomed. 2013, 28, 213-221.

28. Fan, Y.; Sun, Z.; Moradian-Oldak, J. Controlled remineralization of enamel in the presence of amelogenin and fluoride. Biomaterials 2009, 30, 478-483.

29. Fan, Y.; Nelson, J.R.; Alvarez, J.R.; Hagan, J.; Berrier, A.; Xu, X. Amelogenin-assisted ex vivo remineralization of human enamel: Effects of supersaturation degree and fluoride concentration. Acta Biomater. 2011, 7, 2293-2302. 
30. Chen, L.; Liang, K.N.; Li, J.S.; Wu, D.; Zhou, X.D.; Li, J.Y. Regeneration of biomimetic hydroxyapatite on etched human enamel by anionic PAMAM template in vitro. Arch. Oral Biol. 2013, 58, 975-980.

31. Kirkham, J.; Firth, A.; Vernals, D.; Boden, N.; Robinson, C.; Shore, R.C.; Brookes, S.J.; Aggeli, A. Self-assembling peptide scaffolds promote enamel remineralization. J. Dent. Res. 2007, 86, 426-430.

32. Milly, H.; Festy, F.; Watson, T.F.; Thompson, I.; Banerjee, A. Enamel white spot lesions can remineralise using bio-active glass and polyacrylic acid-modified bio-active glass powders. J. Dent. 2014, 42, 158-166.

33. Ruan, Q.; Zhang, Y.; Yang, X.; Nutt, S.; Moradian-Oldak, J. An amelogenin-chitosan matrix promotes assembly of an enamel-like layer with a dense interface. Acta Biomater. 2013, 9, 7289-7297.

34. Ruan, Q.; Siddiqah, N.; Li, X.; Nutt, S.; Moradian-Oldak, J. Amelogenin-chitosan matrix for human enamel regrowth: Effects of viscosity and supersaturation degree. Connect. Tissue Res. 2014, 55, 150-154.

35. Cao, Y.; Mei, M.L.; Li, Q.L.; Lo, E.C.M.; Chu, C.H. Enamel prism-like tissue regeneration using enamel matrix derivative. J. Dent. 2014, 42, 1535-1542.

36. Wu, D.; Yang, J.; Li, J.; Chen, L.; Tang, B.; Chen, X.; Wu, W.; Li, J. Hydroxyapatite-anchored dendrimer for in situ remineralization of human tooth enamel. Biomaterials 2013, 34, 5036-5047.

37. Chen, M.; Yang, J.; Li, J.; Liang, K.; He, L.; Lin, Z.; Chen, X.; Ren, X.; Li, J. Modulated regeneration of acid-etched human tooth enamel by a functionalized dendrimer that is an analog of amelogenin. Acta Biomater. 2014, 10, 4437-4446.

38. Li, Q.L.; Ning, T.Y.; Cao, Y.; Zhang, W.B.; Mei, M.L.; Chu, C.H. A novel self-assembled oligopeptide amphiphile for biomimetic mineralization of enamel. BMC Biotechnol. 2014, 14, 32.

39. Hsu, C.C.; Chung, H.Y.; Yang, J.M.; Shi, W.; Wu, B. Influences of ionic concentration on nanomechanical behaviors for remineralized enamel. J. Mech. Behav. Biomed. Mater. 2011, 4, 1982-1989.

40. Chung, H.Y.; Li, C.C.; Hsu, C.C. Characterization of the effects of 3DSS peptide on remineralized enamel in artificial saliva. J. Mech. Behav. Biomed. Mater. 2012, 6, 74-79.

41. Chung, H.Y.; Li, C.C. Microstructure and nanomechanical properties of enamel remineralized with asparagine-serine-serine peptide. Mate. Sci. Eng. C. Mater. Biol. Appl. 2013, 33, 969-973.

42. Hsu, C.C.; Chung, H.Y.; Yang, J.M.; Shi, W.; Wu, B. Influence of 8DSS peptide on nano-mechanical behavior of human enamel. J. Dent. Res. 2011, 90, 88-92.

43. Chung, H.Y.; Li, C.C. Asparagine-serine-serine peptide regulates enamel remineralization in vitro. J. Mater. Res. 2013, 28, 2890-2896.

44. Li, L.; Mao, C.; Wang, J.; Xu, X.; Pan, H.; Deng, Y.; Gu, X.; Tang, R. Bio-inspired enamel repair via Glu-directed assembly of apatite nanoparticles: An approach to biomaterials with optimal characteristics. Adv. Mater. 2011, 23, 4695-4701.

45. Ravindranath, R.M.; Moradian-Oldak, J.; Fincham, A.G. Tyrosyl motif in amelogenins binds N-acetyl-D-glucosamine. J. Biol. Chem. 1999, 274, 2464-2471.

46. Iijima, M.; Moradian-Oldak, J. Control of apatite crystal growth in a fluoride containing amelogenin-rich matrix. Biomaterials 2005, 26, 1595-1603. 
47. Chen, H.; Banaszak Holl, M.; Orr, B.G.; Majoros, I.; Clarkson, B.H. Interaction of dendrimers (artificial proteins) with biological hydroxyapatite crystals. J. Dent. Res. 2003, 82, 443-448.

48. Dong, Z.H.; Chang, J.A.; Zhou, Y.; Lin, K.L. In vitro remineralization of human dental enamel by bioactive glasses. J. Mater. Sci. 2011, 46, 1591-1596.

49. Beniash, E.; Metzler, R.A.; Lam, R.S.; Gilbert, P.U. Transient amorphous calcium phosphate in forming enamel. J. Struct. Biol. 2009, 166, 133-143.

50. Cao, Y.; Mei, M.L.; Xu, J.; Lo, E.C.; Li, Q.; Chu, C.H. Biomimetic mineralisation of phosphorylated dentine by CPP-ACP. J. Dent. 2013, 41, 818-825.

51. Featherstone, J.D. The science and practice of caries prevention. J. Am. Dent. Assoc. 2000, 131, 887-899.

52. Iijima, M.; Tohda, H.; Suzuki, H.; Yanagisawa, T.; Moriwaki, Y. Effects of F- on apatite-octacalcium phosphate intergrowth and crystal morphology in a model system of tooth enamel formation. Calcif. Tissue Int. 1992, 50, 357-361.

(C) 2015 by the authors; licensee MDPI, Basel, Switzerland. This article is an open access article distributed under the terms and conditions of the Creative Commons Attribution license (http://creativecommons.org/licenses/by/4.0/). 